\title{
Perceived Knowledge and Attitudes Pertaining to 'People with Mental Illness (PwMI)’: A Sri Lankan Perspective
}

\author{
Buddhiprabha D D Pathirana ${ }^{1} *$
}

\section{ABSTRACT}

Conceptions of mental illness are often decided by the socio-cultural background and other socio-demographic factors. The aim of the present study was to assess the perceived knowledge, attitudes and perceived behaviors pertaining to mental illness within the Sri Lankan public. In order to achieve this aim, 167 participants (Females = 97; Males = 70) from 17districts in Sri Lanka were given a survey questionnaire to assess their knowledge, attitudes and perceived practices towards PwMI. The results conveyed that in general participants had high to moderate knowledge, were open minded, displayed pro-integrated attitudes and high to moderate sensitivity towards PwMI. Results also conveyed that there is a positive relationship among knowledge, attitudes, and perceived behaviors towards PwMI.

Keywords: Mental Illness, Attitudes, Knowledge, Perceived Behaviors, Sri Lanka

Decades of global research have established that the public holds negative beliefs that People with Mental Illnesses (PwMI) are dangerous, unpredictable, unattractive, and unworthy. The literature also conveys that public view PwMI are unlikely to be productive members of their communities. Moreover, these negative perceptions have been remarkably constant across regions, culture (Singh, Singh, \& Singh, 2013), and geographical areas(Corrigan, Watson, Warpinski, \& Gracia, 2004); despite advances in scientific understanding of mental illness. As a result, individuals with serious mental illnesses being stigmatized by the society seem to be a universal phenomenon.

Corrigan, (2000), states those individuals who believe that PwMI is dangerous are more likely to react with fear and would attempt to socially avoid PwMI, thereby withholding PWMI's rightful life opportunities. Further, an individual's mental illness would withhold them from their rightful life opportunities. Thus, societal reaction to mental illness, especially severe mental illness may result in stigma and discrimination. It may also unjustly inhibit the person with a psychiatric disability from attaining work, affiliation, and other independent living opportunities (Corrigan,

\footnotetext{
${ }^{1}$ Senior Lecturer in Psychology, Department of Philosophy \& Psychology, University of Peradeniya, Sri Lanka *Responding Author

(C) 2016 Pathirana B; licensee IJIP. This is an Open Access Research distributed under the terms of the Creative Commons Attribution License (http://creativecommons.org/licenses/by/2.0), which permits unrestricted use, distribution, and reproduction in any Medium, provided the original work is properly cited.
} 


\section{Perceived Knowledge and Attitudes Pertaining to 'People with Mental Illness (PwMI)': A Sri Lankan Perspective}

2004). Even though clinical psychology and other disciplines have been instrumental in developing varied psycho-pharmacological and rehabilitation strategies that successfully address psychiatric disease and its sequel; such interventions have not been sufficient to improve the course of mental illness in the absence of societal stigma. Therefore, the importance of identifying the presence, prevalence, nature and the strategies to address societal stigma and discrimination looms large. Moreover, due to culture, traditions and conventional beliefs pertaining to the PwMI in the South Asian milieu, individuals belonging to South Asia may be comparatively affected more than PwMI in the Western world.

In the South Asian context, individuals who are affected by mental illnesses do not receive the same care, support, and importance that physically ill receive. For instance, when a person is affected by physical illness he/she cannot carry out his normal role and therefore assumes the role of a sick person. This benefits him/her in two ways: first, it permits him/her to give up his/her usual responsibilities, and second, he/she becomes the focus of the care and attention of members of the family and society. On the contrary, when a person suffers from mental illness he/she is not provided with the same care and attention that a physically ill person receives due to the fact that mental illness is not been well understood by the general public in Asia. This could be due to several reasons such as the poor attitudes, and knowledge towards PwMI as well as stigmatization. Research conveys that individuals labeled mentally ill, regardless of the specific psychiatric diagnosis or level of disability, are stigmatized more severely than those with other health conditions (Weiner, Magnusson, \& Perry, 1988).

Social psychologists have identified various cognitive and behavioral structures that comprise stigma. Understanding these theoretical structures appears to be important when conducting research to explore the nature, type, and prevalence of stigma as well as when designing intervention programs to address it. According to these theoretical structures, stereotypes as well as available knowledge structures about groups of people (Hilton \& von Hippel, 1996; Judd \& Park, 1993); (e.g., all police officers are good people to seek out when in trouble) serve as important factors of understanding perceptions towards PwMI. Literature conveys that stereotypes serve as efficient anchors due to the fact that they are relatively effortless and accessible processes that govern understanding of a social group (Hamilton \& Sherman, 1994). Thus, those who endorse these stereotypes are likely to react in a discriminatory manner.

When trying to understand the impact of stigma associated with mental illness, researchers distinguish between public stigmas (ways in which the public reacts to a group based on stigma pertaining to that group) and self-stigma (the reactions which individuals have towards themselves due to the fact that they are members of a stigmatized group) (Corrigan, 2000). Research suggests most members of the public are aware of mental illness stereotypes (Bhugra, 1989; Link, 1987) while there is a lacuna for studies which explore the latter. 


\section{Perceived Knowledge and Attitudes Pertaining to 'People with Mental Illness (PwMI)': A Sri Lankan Perspective}

Factor analytic research has identified several stereotypes that are especially problematic for mental illness (Brockington, Hall \& Levings, 1993; Taylor \& Dear, 1980). As its outcome, the range of contemporary behavioral responses to the public stigma of mental illness has been categorized into four groups. They are 1. Withholding help (e.g. choosing not to assist a PwMI because they are believed to be responsible for their lot in life); 2. Avoidance (e.g. reluctance/refusal of the landlords lease properties to PwMI or employers who do not hire them); 3. Segregation (e.g. actions that promote PwMI away from their community into institutions where they can be better treated or controlled); and 4.Coercion (mandatory treatment or criminal justice responses based on the belief that PwMI are not able to make competent life decisions) (Corrigan, Markowitz, Watson, Rowan \& Kubiak, 2002).

The quality and effectiveness of mental health treatments and services have comparatively improved over the past two decade within the South Asian milieu including Sri Lanka. However, there has been limited research in the area of stigma and mental illness in the Sri Lankan milieu. The available handful of literature convey that despite distinctive improvements in the standards of mental health care in Sri Lanka, allocation of funds (Saxena, Thornicroft, Knapp \& Whiteford, 2007) and service provisions for mental illness are often limited, mostly to custodial care. Although various explanations such as the change in demographics, lack of resources and resource persons (Samarasekara, Davies \&Siribaddana, 2012) are attributed to these existing rudimentary services; one possible explanation impeding provision for people with mental illness (PwMI) may be due to the prevailing knowledge and attitudes towards PwMI shaping public opinion.

Hence, the stigma associated with mental illness; seem to act as an equally overarching barrier preventing the Sri Lankans reaching for it, as much as the limitations in resources. As a result, many Sri Lankans who might benefit from these services may opt not to obtain them or do not fully benefit from it due to the stigma associated with it.

In keeping with this awareness, systematic and dynamic strategies require to be drawn. Globally, a diverse set of initiatives has emerged focusing on efforts to combat stigma and discrimination. However, the efficiency of those endeavors would rest on its ability to comprehend the process of stigma (i.e. factors that produce and sustain such processes, and the mechanisms that lead from stigmatization to harmful consequences).

Hence, it would be essential to measure the scientific understanding of stigma. However, very few studies exist on knowledge, attitudes and behaviors pertaining to mental illness in nonwestern societies (Singh, Singh, \& Singh, 2013; Shrivastava, Johnston, \& Bureau, 2012 especially Sri Lanka (Samarasekara, Davies \& Siribaddana, 2012; Fernando, Deane, McLeod, 2010; Siva, 2010). The available handful of studies have been either carried out with a smaller 


\section{Perceived Knowledge and Attitudes Pertaining to 'People with Mental Illness (PwMI)': A Sri Lankan Perspective}

sample or with medical population (i.e. doctors, medical students) (Fernando et al., 2010) or community health workers (Samarasekara et al., 2012). The present study aims to address this issue by exploring the perceived knowledge, attitudes and behaviors pertaining to PwMI in a sample who represent general public of Sri Lanka.

\section{METHOD}

A self-report questionnaire was developed after reviewing previous literature pertaining to the topic. The broad aim of the questionnaire was to measure knowledge, attitudes and behaviors pertaining to PwMI. Participants were individuals representing different geographical areas in Sri Lankan belonging to diverse socio-economical and educational backgrounds.

The survey questionnaire included a number of statements pertaining to PwMI. Respondents were asked to indicate the extent to which they agreed or disagreed with each statement in a three-point rating scale. The questions covered a range of topics including the participant's knowledge, attitudes and perceived behaviors towards the PwMI.

The outline of the questionnaire could be divided into three sections. They are; 1 . Participants perceived knowledge of mental illnesses ( $n=08$; e.g. I think mental illness can be cured for good, I think mental illnesses are contagious), 2. Participants perceived attitudes towards PwMI ( $\mathrm{n}=$ 11, e.g. 'I think those who have recovered from mental illnesses should be allowed to live in the society as normal people', 'I think those who have recovered from mental illness should be allowed to live in the society as normal people'), and 3. Participants perceived behaviors towards PwMI ( $\mathrm{n}=08$, e.g. 'If a mentally ill person sits next to me when I am traveling in the bus I usually get up from the seat').

\section{Participants}

Participants comprised of diverse group of 167 individuals who came from 17 districts in Sri Lanka (out of 25 districts). The sample comprised of 70 males $(\mathrm{M}=37.97$; S.D $=16.78)$ and $97(\mathrm{M}=36.12$; $\mathrm{S} . \mathrm{D}=16.03)$ females between the age group of 16 to 78 years $(\mathrm{M}=37.74$; $\mathrm{S} . \mathrm{D}=$ 16.5).

Table 01: Characteristics of the sample

\begin{tabular}{|l|l|l|l|}
\hline & $\begin{array}{l}\text { Whole } \\
\text { Sample }\end{array}$ & $35-78$ Yr. & $16-35$ Yr. \\
\hline Sample Size & 167 & 75 & 92 \\
\hline Gender & & & \\
\hline Male & $\mathbf{7 0}$ & 35 & 35 \\
\hline Female & 97 & 40 & 57 \\
\hline Mean Age & & & \\
\hline
\end{tabular}

(C) The International Journal of Indian Psychology, ISSN 2348-5396 (e)| ISSN: 2349-3429 (p) | 27 
Perceived Knowledge and Attitudes Pertaining to 'People with Mental Illness (PwMI)': A Sri Lankan Perspective

\begin{tabular}{|l|l|l|l|}
\hline & $\begin{array}{l}\text { Whole } \\
\text { Sample }\end{array}$ & 35-78 Yr. & $\mathbf{1 6 - 3 5}$ Yr. \\
\hline SD & $\mathbf{1 6 . 5}$ & & \\
\hline Educational Level & $\mathbf{1 6 5}$ & $\mathbf{7 5}$ & $\mathbf{9 0}$ \\
\hline Not completed $10^{\text {th }}$ standard & $\mathbf{1 0}$ & $\mathbf{9}$ & $\mathbf{1}$ \\
\hline G.C.E (O/L) Completed $10^{\text {th }}$ Standard & $\mathbf{5 1}$ & $\mathbf{3 5}$ & $\mathbf{1 6}$ \\
\hline G.C.E (A/L) Completed $12^{\text {th }}$ Standard & $\mathbf{8 2}$ & $\mathbf{2 0}$ & $\mathbf{6 2}$ \\
\hline Degree & $\mathbf{1 2}$ & $\mathbf{3}$ & $\mathbf{9}$ \\
\hline Post Graduate Qualifications) & $\mathbf{0 4}$ & $\mathbf{4}$ & $\mathbf{1}$ \\
\hline Age is not responded to & $\mathbf{6}$ & $\mathbf{5}$ & $\mathbf{1}$ \\
\hline
\end{tabular}

\section{Study Design}

The survey questionnaire was developed after the review of literature on similar research and research tools; developed to assess the knowledge, attitudes and perceived behaviors towards PwMI. Next, the content of the questionnaire was followed-up with a series of exploratory discussions with several experts in the field of psychology and sociology. Based on their suggestions, the preliminary conceptualization, objectives, items and wording were revised. In this process, some elements to the questionnaire were added and changed. Subsequently, the questionnaires were administered to a sub-sample which is similar to the intended sample of participants. Their responses and experiences in filling the questionnaire were recorded. The final version of the questionnaire comprised of 24 items.

\section{RESULTS}

Table 02: Knowledge of PwMI

\begin{tabular}{|c|c|c|c|c|c|c|c|c|}
\hline & \multicolumn{2}{|c|}{ Agree } & \multicolumn{2}{|c|}{$\begin{array}{l}\text { Agree nor } \\
\text { Disagree }\end{array}$} & \multicolumn{2}{|c|}{ Disagree } & \multirow[t]{2}{*}{$\mathbf{M}$} & \multirow[t]{2}{*}{ S.D } \\
\hline & f & $\%$ & $\mathbf{f}$ & $\%$ & $\mathbf{f}$ & $\%$ & & \\
\hline $\begin{array}{l}\text { I believe mental illness can be } \\
\text { cured for good }\end{array}$ & 67 & 40.1 & 72 & 43.1 & 28 & 16.8 & 1.77 & .719 \\
\hline $\begin{array}{l}\text { I think mental illnesses are } \\
\text { contagious }\end{array}$ & 56 & 33.5 & 17 & 10.2 & 94 & 56.3 & 2.23 & .923 \\
\hline $\begin{array}{l}\text { All mental illness has a genetic } \\
\text { predisposition }\end{array}$ & 46 & 27.5 & 42 & 25.1 & 73 & 43.7 & 2.10 & .924 \\
\hline $\begin{array}{l}\text { After mentally ill person recovers } \\
\text { from his mental illness, I think } \\
\text { he/she is competent to take up a } \\
\text { job }\end{array}$ & 87 & 52.1 & 35 & 21 & 44 & 26.3 & 1.73 & .860 \\
\hline $\begin{array}{l}\text { All those with mental illness can } \\
\text { be easily provoked }\end{array}$ & 38 & 22.8 & 87 & 52.1 & 39 & 23.4 & 1.97 & .732 \\
\hline I believe mental illnesses can be & 68 & 40.7 & 62 & 37.1 & 37 & 22.2 & 1.81 & .773 \\
\hline
\end{tabular}

(C) The International Journal of Indian Psychology, ISSN 2348-5396 (e)| ISSN: 2349-3429 (p) | 28 
Perceived Knowledge and Attitudes Pertaining to 'People with Mental Illness (PwMI)': A Sri Lankan Perspective

\begin{tabular}{|l|l|l|l|l|l|l|l|r|}
\hline & \multicolumn{2}{|l|}{ Agree } & \multicolumn{2}{l|}{$\begin{array}{l}\text { Agree nor } \\
\text { Disagree }\end{array}$} & \multicolumn{2}{l|}{ Disagree } & M & S.D \\
\hline & $\mathbf{f}$ & $\%$ & $\mathbf{f}$ & $\mathbf{\%}$ & $\mathbf{f}$ & $\mathbf{\%}$ & & \\
\hline prevented & & & & & & & & \\
\hline $\begin{array}{l}\text { All the mentally ill have below } \\
\text { average intelligence }\end{array}$ & $\mathbf{5 9}$ & 35.3 & $\mathbf{2 3}$ & 13.8 & $\mathbf{8 5}$ & 50.9 & $\mathbf{2 . 1 6}$ & .918 \\
\hline $\begin{array}{l}\text { In order to recover, people with } \\
\text { mental illnesses need care and love } \\
\text { as much as medicine }\end{array}$ & $\mathbf{1 0 1}$ & 60.5 & $\mathbf{0 7}$ & $\mathbf{4 . 2}$ & $\mathbf{5 8}$ & $\mathbf{3 4 . 7}$ & $\mathbf{1 . 7 3}$ & .953 \\
\hline
\end{tabular}

$N=165 ;$ Minimum = 07; Maximum $=24 ;$ Mean $=17.39 ;$ S.D $=4.872$

Table 2 represents the outcomes of the participants' perceived knowledge pertaining to causes of mental illness, characteristics of PwMI, factors which impact mental illness, the participant's perceived capacity and the competency of the PwMI after recovery.

Results convey that significant percentage of the participants seem to agree with the statement that mental illness can be cured for good (Agree $=67 ; 40.1 \%$ ). Comparatively few seem to disagree with it $(28,16.8 \%)$ while majority seem to feel uncertain about it $(72,43.1 \%)$. The next statement explored the participants' knowledge pertaining to the cause of mental illness being contagious. Large number of participants $(n=94 ; 56.3 \%)$ seem to disagree with this statement while one third agreed with it $(n=56,33.51 \%)$.

Similarly, majority seem to disagree with the statement that mental illness has a genetic predisposition (Disagree $=73,43.7 \%$ ) while almost one third of the participants agree with it (Agree $=46,27.5 \%$ ). The fourth statement explored the participants' opinion pertaining to the competency of PwMI to be employed after their recovery. Again the majority of the participants seemed to believe that after their recovery PwMI is competent to be employed (Agree = 87; $52.1 \%$ ); while less than almost one fourth of the participants have disagreed with this statement (Disagree $=44,26.3 \%)$.

On the other hand, majority of the participants were uncertain about the statement that 'All those with mental illness can be easily provoked' (uncertain $=87,52.1 \%$ ) while equal number seem to agree $(n=38,22.8 \%)$ and disagree $(n=39,23.4 \%)$ with it. Even though majority of the participants have agreed with the sixth statement that 'I believe mental illness can be prevented ( $\mathrm{n}=68 ; 40.7 \%)$; almost equal number of participants seemed to be uncertain about it $(\mathrm{n}=62$, $37.1 \%)$ while one-fifth has disagreed with it $(n=37 ; 22.2 \%)$. The seventh statement (all the mentally ill have below average intelligence); seemed to have generated disagreement from the majority ( $n=85 ; 50.9 \%)$ while more than one-third have agreed with it $(n=59 ; 35.3 \%)$. Finally, the last statement which explored the care and protection available to the PwMI (i.e. In order to 


\section{Perceived Knowledge and Attitudes Pertaining to 'People with Mental Illness (PwMI)': A Sri Lankan Perspective}

recover, people with mental illnesses need care and love as much as medicine) seemed to have generated the consensus of the majority $(\mathrm{n}=101 ; 60.5 \%)$ while little more than one third $(\mathrm{n}=$ 58; 34.7\%) of the participants disagreed with it.

The maximum value of the knowledge pertaining to PwMI was 24 while the minimum was 07. The results $(M=17.39)$ conveyed that participants have an overall high knowledge pertaining to PwMI, believing that they deserve the care and protection of the community as well as right to be integrated into the community after their recovery as fully functioning entities.

Table 03: Perceived attitudes towards PwMI

\begin{tabular}{|c|c|c|c|c|c|c|c|c|}
\hline & \multicolumn{2}{|c|}{ Agree } & \multicolumn{2}{|c|}{$\begin{array}{l}\text { Agree nor } \\
\text { Disagree }\end{array}$} & \multicolumn{2}{|c|}{ Disagree } & \multirow[t]{2}{*}{$M$} & \multirow[t]{2}{*}{ S.D } \\
\hline & $f$ & $\%$ & $f$ & $\%$ & $f$ & $\%$ & & \\
\hline $\begin{array}{l}\text { I think those who have recovered } \\
\text { from mental illness should be } \\
\text { allowed to live in the society as } \\
\text { normal people }\end{array}$ & 72 & 43.1 & 43 & 25.7 & 52 & 31.1 & 1.88 & .856 \\
\hline $\begin{array}{l}\text { When a person with mental illness } \\
\text { recovers from it I consider } \\
\text { him/her as a normal person-10 }\end{array}$ & 84 & 50.3 & 30 & 18 & 51 & 30.5 & 1.78 & .901 \\
\hline $\begin{array}{l}\text { I think mentally ill should be } \\
\text { shown sympathy }\end{array}$ & 95 & 56.9 & 17 & 10.2 & 55 & 32.9 & 1.76 & .920 \\
\hline $\begin{array}{l}\text { Even when a person with a mental } \\
\text { illness recovers completely from } \\
\text { his/her mental illness I think } \\
\text { he/she is not to fit to marry a } \\
\text { normal person }\end{array}$ & 55 & 32.9 & 40 & 24 & 72 & 43.1 & 2.10 & .869 \\
\hline $\begin{array}{l}\text { If there is a person with mental } \\
\text { illness in my family I think I might } \\
\text { try to hide it from the society }\end{array}$ & 46 & 27.5 & 66 & 39.5 & 54 & 32.3 & 2.03 & .791 \\
\hline $\begin{array}{l}\text { I like to visit a person with mental } \\
\text { illness when they have been } \\
\text { hospitalized to treat for his/her } \\
\text { illness }\end{array}$ & 86 & 51.5 & 26 & 15.6 & 55 & 32.9 & 1.81 & .903 \\
\hline
\end{tabular}

$N=165 ;$ Minimum = 06; Maximum = 18; Mean = 12.9 Median = 14; Mode = 16;.$D$ D = 3.92

This section of the study explored the participants' attitudes pertaining to the PwMI. In response to first attitude statement('I think those who have recovered from mental illness should be allowed to live in the society as normal people'), has generated positive response from the majority of the participants (Agree $=72 ; 43.1 \%$ ) while one-third of the participants have disagreed with it (Disagree $=52 ; 31.1 \%$ ). The second statement also was similar and explored the participants' specific attitude towards PwMI (When a person with mental illness recover 


\section{Perceived Knowledge and Attitudes Pertaining to 'People with Mental Illness (PwMI)': A Sri Lankan Perspective}

from it I consider him/her as a normal person). In response to this again the majority of the participants have provided positive responses (Agree $=84 ; 50.3 \%$ ) while about one-third (Disagree $=51 ; 30.5 \%$ ) have disagreed with it. Majority of the participants have also agreed that PwMI should be shown sympathy $(\mathrm{n}=95 ; 56.9 \%)$ while almost one third $(\mathrm{n}=55 ; 32.9 \%)$ seem to think that they do not. The fourth statement examined the participants' attitudes towards PwMI's right to marry after their recovery from the mental illness, a significant number of participants' seemed to be of the opinion that they are not fit enough do so $(n=55,32.9 \%)$, while majority seemed to be of the opinion that PwMI can marry $(n=72,43.1 \%)$. On the other hand, the participants seemed to have mixed opinions pertaining to the mental illness of a family member. Again, significant number of participants seemed to believe that if a family member suffers from mental illness they would attempt to hide it from the society $(\mathrm{n}=46,27.5 \%)$ while almost an equal number mentioned that they would not ( $\mathrm{n}=54,32.3 \%)$. However, significant number of participants seemed to be uncertain about their actions $(n=66,39.4 \%)$. On the other hand, majority of the participants seemed to be receptive to idea that that they would visit a PwMI in the hospital (Agree $=86 ; 51.5 \%$ ) while little less than one third disagreed with it.

The maximum value for attitudes pertaining to PwMI was 18 while the minimum was 06 . The outcome of the total attitudes $(\mathrm{M}=12.9$; Mode $=16$; Median =14; $\mathrm{S} . \mathrm{D}=3.92)$ conveyed that participants have displayed more sensitivity towards PwMI.

Table 04: Perceived behaviors of the participants pertaining to PwMI

\begin{tabular}{|l|l|l|l|l|l|l|l|l|l|}
\hline & \multicolumn{2}{|l|}{ Agree } & \multicolumn{2}{l|}{$\begin{array}{l}\text { Agree nor } \\
\text { Disagree }\end{array}$} & \multicolumn{2}{l|}{ Disagree } & M & S.D \\
\hline & $\boldsymbol{f}$ & $\%$ & $\boldsymbol{f}$ & $\mathbf{\%}$ & $\boldsymbol{f}$ & $\mathbf{\%}$ & & \\
\hline $\begin{array}{l}\text { If a mentally ill person sits next to } \\
\text { me when I am traveling in the bus } \\
\text { I usually get up from the seat }\end{array}$ & $\mathbf{4 9}$ & 29.3 & $\mathbf{7 0}$ & 41.9 & $\mathbf{4 6}$ & 27.5 & $\mathbf{1 . 9 6}$ & .787 \\
\hline $\begin{array}{l}\text { When on the road if I meet a } \\
\text { person with mental illness I ignore } \\
\text { him/her }\end{array}$ & $\mathbf{4 8}$ & 28.7 & $\mathbf{7 0}$ & 41.9 & $\mathbf{4 8}$ & 28.7 & $\mathbf{1 . 9 9}$ & .776 \\
\hline $\begin{array}{l}\text { When I see a person with mental } \\
\text { illness I make fun of him/her }\end{array}$ & $\mathbf{5 8}$ & 34.7 & $\mathbf{0 7}$ & 4.2 & $\mathbf{1 0 1}$ & 60.5 & $\mathbf{2 . 2 5}$ & .96 \\
\hline $\begin{array}{l}\text { I have visited a person with mental } \\
\text { illness when he/she has been } \\
\text { hospitalized }\end{array}$ & $\mathbf{8 2}$ & 49.1 & $\mathbf{0 9}$ & $\mathbf{5 . 4}$ & $\mathbf{7 3}$ & $\mathbf{4 3 . 7}$ & $\mathbf{1 . 9 1}$ & .999 \\
\hline $\begin{array}{l}\text { I have insulted a person with } \\
\text { mental illness by calling him } \\
\text { 'mad' or such other terms }\end{array}$ & $\mathbf{5 9}$ & 35.3 & $\mathbf{1 8}$ & $\mathbf{1 0 . 8}$ & $\mathbf{9 0}$ & $\mathbf{5 3 . 9}$ & $\mathbf{2 . 1 9}$ & .929 \\
\hline
\end{tabular}

$N$ = 164; Minimum = 05; Maximum = 15; Mean = 10.41; S.D = 2.535; Median = 11; Mode = 11 
This section explored the participants' perceived behavior towards PwMI. Participants seemed to have mixed opinions on sitting next to a PwMI (Agree $=49$; 29.3\%; Agree nor Disagree $=70$; 41.9\%;) as well as ignoring PwMI (Agree nor Disagree $=70$; 41.9\%;). Less than one-third of the participants seemed to have perceived that they would not get up from their seats if a PwMI sits next to them (Disagree $=46,27.5 \%$ ) or not ignore PwMI (Disagree $=48,28.7 \%$ ). On the other hand, the majority of the participants seemed to have perceived that they would not make fun of a PwMI (Disagree $=101,60.5 \%)$ or have insulted a PwMI (Disagree $=90,53.9 \%)$ in the past. However, more than one-third have agreed with both the statements. Similarly, even though almost fifty percent (Agree $=82,49.1 \%$ ) of the participants perceived that they have visited a PwMI in the hospital, over forty percent have reported that they have not (Disagree $=73$, 43.7\%).

The maximum value for attitudes pertaining to PwMI was 15 while the minimum was 05 . The outcome of the total behaviors $(\mathrm{M}=10.41$; Mode $=11$; Median $=11)$ conveyed that participants have displayed fair to moderate sensitivity towards PwMI in their behaviors.

Table 05: Participant perceptions pertaining to knowledge, attitudes, and behaviors towards PwMI: Correlations and descriptive statistics ( $n=167)$.

\begin{tabular}{|l|l|l|l|}
\hline & $\mathbf{1}$ & $\mathbf{2}$ & $\mathbf{3}$ \\
\hline Knowledge & - & & \\
\hline Attitudes & $.894^{* *}$ & - & \\
\hline Behaviors & $.632^{* *}$ & $.701^{* *}$ & - \\
\hline
\end{tabular}

Note: **. Correlation is significant at the 0.01 level (2-tailed).

Participants perceived knowledge towards PwMI was positively correlated with perceived attitudes $(\mathrm{r}=.894, \mathrm{p}<.01)$ and perceived behaviors $(\mathrm{r}=.701, \mathrm{p}<.01)$.

\section{DISCUSSION}

The present study focused on knowledge, attitude and perceived behaviors of the representative sample of Sri Lankans pertaining to PwMI. The primary aim of the study was to explore the whether there is a relationship among perceived knowledge, attitudes and perceived behaviors towards PwMI. Results of the study convey that there is a positive relationship among these three variables.

The results report that participants' knowledge pertaining to PwMI records a high value. They seemed well-informed about certain aspects, such as the causes of mental illness, unfavorable treatment and care/protection required for the PwMI. Similarly, the study also reports high sensitivity reflected in the attitudes as well as fair to moderate perceived treatment for PwMI. 


\section{Perceived Knowledge and Attitudes Pertaining to 'People with Mental Illness (PwMI)': A Sri Lankan Perspective}

Thus, several conclusions can be drawn from this study, with the most important being a high to moderate knowledge, generally positive attitude towards PwMI and perceived acts of fair to moderate sensitivity towards PwMI. However, this generally high knowledge, positive attitude and perceived acts of sensitivity seemed to be hampered by the lack of Knowledge, negative attitudes and perceived insensitive behaviors towards PwMI, reflected by the high rates of "uncertain” or “Agree nor Disagree” responses to certain statements.

Studies which have examined the effects of education on attitudes about severe mental illness conveys that members of the general public who have more knowledge about mental illness are less likely to endorse stigmatizing attitudes (Link et al. 1987; Brockington et al.1993).Results from the previous studies have conveyed that social and demographic characteristics tend to arouse distinctive perceived knowledge differences and attitudes towards PwMI (Bhugra \& Cutter, 2001; Taylor \& Dear 1981).However, this study did not explore the participants' educational level with their knowledge. Thus, based on these findings the present study recommends a systematic exploration of the knowledge of the Sri Lankan general public on PwMI on a larger sample representing varied geographical locations, age groups, educational levels, and ethnic/religious contexts.

The participant's attitudes towards PwMI seemed to be generally in a positive direction, even though they appear to be related to traditional beliefs in a complex manner. However, such beliefs cannot be accurately gauged using quantitative methods of data collection. Therefore, the present study suggests that future research needs to explore the impact of traditional beliefs on the attitudes towards PwMI through qualitative procedures.

Moreover, even though attitudes expressed pertaining to social acceptance of PwMI among these participants were generally positive, a substantial proportion of the sample held negative views about PwMI and expressed their reluctance to accept and interact with PwMI. Hence, this study also identifies the importance of greater awareness and sensitivity towards PwMI. Again research conveys that education and awareness lead to improvement in benevolence and decreased social discrimination of PwMI (Holmes, Corrigan, Williams, Canar, \& Kubiak (1999). Therefore, it is believed that clearer insights have been procured from the study if the correlations were to be drawn among knowledge, attitudes and educational levels. Again, an endeavour recommended for future studies.

Further, findings convey that older people tend to exhibit more negative attitudes toward PwMI in spite of their life experience, because they are more likely to be conventional and to reject odd behavior (Ewalds-Kvist, Högberg, \& Lützén, 2012). However, other researches depict that age does not create a significant effect on the attitudes (Singh et al., 2013). Ewalds-Kvist, Högberg, \& Lützén (2012) report that as age increased, so did the attitudes of open-mindedness and pro- 
integration relative to PwMI. Therefore, future studies also need to explore the relationship between age and knowledge, attitudes \&perceived behaviors pertaining to PwMI.

Finally, some limitations of the present study should be mentioned. In the traditional Sri Lankan context the word 'madness' is often associated with demonic possessions. However, the survey questionnaire did not contain questions to assess this aspect. Therefore, future research needs to explore this facet in more detail. Moreover, the study would have depicted clearer and accurate picture of participant's knowledge pertaining to PwMI if the questions such as 'Mental illness has a genetic predisposition' had been rephrased as 'all types of mental illness has a genetic predisposition'.

As with other attitude studies, it remains an open question as to what extent the behavioral intentions measured by the construct actually translate into concrete behavior. Hence, findings may reflect 'social desirability bias' rather than actual practices. However, a meta-analysis of all relevant studies suggests that there is a substantial relationship between attitudes and behavior (Kraus, 1995). Further, it is also possible that the sample, despite its relative diversity, was not fully representative of the national population of Sri Lankans. For example, participants who agreed to participate in the present study may have had a greater interest in or more accepting ideas about mental illness than those who did not participate.

The present study explored the perceptions of mental illness on a generic sample of Sri Lankans. Thus, it adds to the global knowledge on this subject, providing data from a South Asian developing country. However, it also calls for more in-depth information in this area.

\section{Acknowledgments}

The author appreciates all those who participated in the study and helped to facilitate the research process.

\section{Conflict of Interests}

The author declared no conflict of interests.

\section{REFERENCES}

Bhugra D ., \& Cutter W . (2001). Mentally ill: Public attitudes . International encyclopedia of the social \& behavioral sciences, $9665-9$.

Brockington, I. F., Hall, P., Levings, J., \& Murphy, C. (1993). The community's tolerance of the mentally ill. British Journal of Psychiatry,162, 93-99.

Corrigan, P. W. (2000). Mental health stigma as social attribution: Implications for research methods and attitude change. Clinical Psychology—Science \& Practice, 7, 48-67. 


\section{Perceived Knowledge and Attitudes Pertaining to 'People with Mental Illness (PwMI)': A Sri Lankan Perspective}

Corrigan, P. W., Watson, A. C., Warpinski, A. C., \& Gracia, G. (2004), "Stigmatizing attitudes about mental illness and allocation of resources to mental health services", Community Ment. Health J., 40 (4), 297-307.

Corrigan, P.W., Markowitz, F.E., Watson, A.C., Rowan, D., \&Kubiak, M.A. (2003).An attribution model of public discrimination towards persons with mental illness. Journal of Health \& Social Behavior, 44(2), 162-179.

Ewalds-Kvist B., Högberg T., \& Lützén, K. (2012). The impact of gender and age on attitudes towards mental illness in Sweden. Nord J Psychiatry, Early online, 1-9.

Fernando S.M., Deane F.P., McLeod, H. (2010). Sri Lankan doctors' and medical undergraduates’ attitudes towards mental illness. Soc Psychiatry Psychiatr Epidemiology, 45(7), 733-739.

Hamilton, D., \& Sherman,J. (1994). Stereotypes In. R. S. Wyer \& T.K. Srull (Eds.), Handbook of social cognition (2nd ed., pp. 1-68).Hills- dale,N J:Erlbaum.

Hilton, J. L. \& von Hippel, W. (1996). Stereotypes. Annual Review of Psychology, 47, 237-271.

Holmes, E. P., Corrigan, P. W., Williams, P., Canar, J., \& Kubiak, M.(1999). Changing public attitudes about schizophrenia. Schizophrenia Bulletin, 25,447-456.

Judd, C. M., \& Park, B. (1993). Definition and assessment of accuracy in social stereotypes. psychological Review, 100, 109-128.

Kraus, S.J. (1995). Attitudes and the prediction of behavior: a met analysis of the empirical literature. Pers. Soc. Psychol. Bull. 21, 58- 75.

Link, B.G.(1987). Understanding labeling effects in the area of mental disorders: An assessment of the effects of expectations of rejection. American Sociological Review, 52:96-112.

Samarasekara N, Davies M.,L.M., \& Siribaddana S. (2012). The stigma of mental illness in Sri Lanka: the perspectives of community mental health workers. Stigma Research and Action, 2(2):93-99.

Saxena, S., Thornicroft, G., Knapp, M., \& Whiteford, H. (2007). Resources for mental health: Scarcity, inequity, and inefficiency. Lancet, 370,878-889.

http://dx.doi.org/10.1016/S0140-6736(07)61239-2

Siva, N. (2010), Sri Lanka struggle with mental health burden, the Lancet, 375, 80-81.

Shrivastava, A., Johnston, M., \& Bureau, Y. (2012). The stigma of Mental Illness-1: Clinical reflections. Mens Sana Monographs, 10(1), 70-84. http://doi.org/10.4103/09731229.90181

Singh, B., Singh, R., \& Singh, K.K. (2013) Knowledge and attitude towards mental health and mental illness: an issue among rural and urban community of Jhapa district of Nepal. International Journal of Health Science \& Research, 3(9), 29-34.

Taylor S., \& Dear M. (1981). Scaling community attitudes toward the mentally ill. Schizoph Bull, 7, $225-40$.

Weiner, B., Magnusson, J., \& Perry, R. P. (1988). An attributional analysis of reactions to stigmas. Journal of Personality and Social Psychology, 55, 738-748. 
Perceived Knowledge and Attitudes Pertaining to 'People with Mental Illness (PwMI)': A Sri Lankan Perspective

Weller, L., and Grunes, S. (1988), Does contact with the mentally ill affect nurses; attitudes to mental illness?. British Journal of Medical Psychology, 61: 277-284. doi: 10.1111/j.2044-341.1988.tb02789.x

How to cite this article: Pathirana B (2016), Perceived Knowledge and Attitudes Pertaining to 'People with Mental Illness (PwMI)': A Sri Lankan Perspective, International Journal of Indian Psychology, Volume 4, Issue 1, No. 80, ISSN:2348-5396 (e), ISSN:2349-3429 (p), DIP:18.01.103/20160401, ISBN:978-1-365-57867-0 